\title{
An improved method for quantitative risk assessment of unconfined offshore installations subjected to gas explosions
}

\author{
Yuxin Xu ${ }^{\mathrm{a}}$, Yong Bai ${ }^{\mathrm{a}, \mathrm{b}}$, Jeom Kee Paik ${ }^{\mathrm{c}, \mathrm{d}}$, Weishun Dai ${ }^{\mathrm{a}}$ \\ a. College of Civil Engineering and Architecture, Zhejiang University. \\ 310058, Hangzhou, China \\ b. Ningbo OPR Offshore Engineering Co. Ltd \\ 315500 , Ningbo, China \\ c. Department of Mechanical and Engineering, University College London \\ WC1E 7JE, London, United Kingdom \\ d. The Korea Ship and Offshore Research Institute, Pusan National University \\ 609-735, Busan, Korea
}

\begin{abstract}
Previous related research has focused on consequences analysis of confined rather than unconfined structures against explosion accidents. This paper introduces an improved method for quantitative risk assessment of unconfined offshore installations subjected to gas explosions. In the present study, a floating, production, storage, and offloading unit (FPSO) is given as an example to present the proposed method. Instead of the most unfavorable scenario, lots of random scenarios are selected by the probabilistic sampling approach. The method for determining the equivalent gas cloud position is illustrated in the conversion between dispersion and explosion scenarios. Maximum and average overpressures are obtained by computational fluid dynamics (CFD) simulation. Besides overpressure exceedance curves, the combination of overpressure and probability method is adopted based on the definition of risk. This work allows finer scenarios' sampling results and reduces the computational costs.
\end{abstract}

\section{Key Words}

Quantitative risk assessment; Gas explosions; Gas cloud position; Overpressure-probability combination

\section{Introduction}

A series of major disasters such as fires and explosions have sounded the alarm for the development of the offshore oil industry worldwide. HSE [1] reported that fire and explosion are identified as major hazards causing serious casualties, property losses and marine pollution among more than 60 offshore accidents that happened in the past 40 years. Therefore, the safety of offshore installations operating in harsh environments has placed an urgent need for studying the evolution of major disasters and risk assessment of the whole system.

An extreme or accidental event in a structural system is always associated with multiple parameters that are random and probabilistic by nature. Therefore, a huge number of possible scenarios must be relevant to the real event. However, it is unrealistic to simulate all possible scenarios. As such a selection must be made. In the current industry practice, only a single scenario or at most a few scenarios are considered to represent the so-called "most unfavorable" event. Such scenarios obviously cannot represent the physics of reality. Therefore, it is essential to select a set of realistic scenarios that must represent all the possible events but with a limited number which is needed to minimize the computational costs.

A lot of efforts have been put into the prediction and selection of gas explosion scenarios in offshore installations [2][3][4][5][6]. API RP WSD [7] provides a selection process for screening out high-risk fire and explosion scenarios, but it still relies on expert's experience and judgment to further refine those scenarios. UKOOA [8] put forward some guiding ideas for representative scenario selection and the calculating method of accident probabilities, which is valuable for putting scenario selection into practice. Paik and Czujko [9] proposed a quantitative procedure that randomly 
generates fire and explosion scenarios by input several random variables associated with individual probability distribution functions. This method takes advantage of digital technologies instead of relying on human experience and insights. Based on the probability statistical theory and stochastic sampling modeling technology, different variables are considered in this paper, which reduces computational costs and gets accurate results at the same time.

A framework for the quantitative risk assessment of explosion accidents requires both the probabilities and consequences evaluation. While considerable attention has been paid to consequences analysis [10][11][12][13], literature combing the probabilities and consequences have emerged relatively slowly and in a more scattered way [14][15]. Moreover, consequence simulations are mostly done with the help of commercial software [16][17]. Software users need to rely on their engineering experience to accurately input every parameter and adjust these parameters to achieve the best effect, which makes the calculating results inevitably subjective. Quantitative assessment based on numerical simulation tools and field trials, such as Computational Fluid Dynamics (CFD), rather than qualitative assessment relying on engineering experience, has begun to be more extensively applied in offshore designs [18][19][20].

A gas explosion is an explosion resulting from mixing a gas, typically from a gas leak, with air in the presence of an ignition source. Isolated recent efforts have been made to investigate flammable gas leak, dispersion, explosion or risk assessment, but different target structures are used in the above studies [21][22][23]. The discontinuity of the whole accident simulation reduces the accuracy of the assessment results to some extent. Explosion risks are always related to three critical conditions, which are confinement, congestion, and ventilation [15]. Extensive literature [24][25] has focused on the quantitative risk assessment of specific facilities subjected to gas explosions, but comparatively little research cared about the whole offshore installations [26][27]. Various conditions in the surrounding environment, such as the distribution of facilities, significantly affect gas dispersion characteristics and subsequent consequences of explosions. Moreover, much more severe consequences may happen due to a larger volume of gas formed in the large space. It is necessary to consider the interaction of different parts of offshore installations and different stages of gas explosions when doing the quantitative risk assessment.

In this paper, an authentic FPSO is used as an example to present an improved method for quantitative risk assessment of unconfined offshore installations subjected to gas explosions. Eight affecting parameters are sampled to define the gas dispersion scenarios. Leak facility is first determined and then the environmental conditions. Sets of gas dispersion scenarios are obtained by the probabilistic sampling approach. The method of determining gas cloud position is given in the conversion of dispersion and explosion scenarios. The maximum and average overpressures are then obtained in CFD simulation. The overpressure-probability combination method is proposed based on the concept of risk and verified by overpressure exceedance curves.

\section{General procedure for quantitative risk assessment of flammable gas explosions}

Fig. 1 presents procedures for quantitative risk assessment (QRA) of flammable gas explosions. The procedure of QRA can be classified into 3 phases.

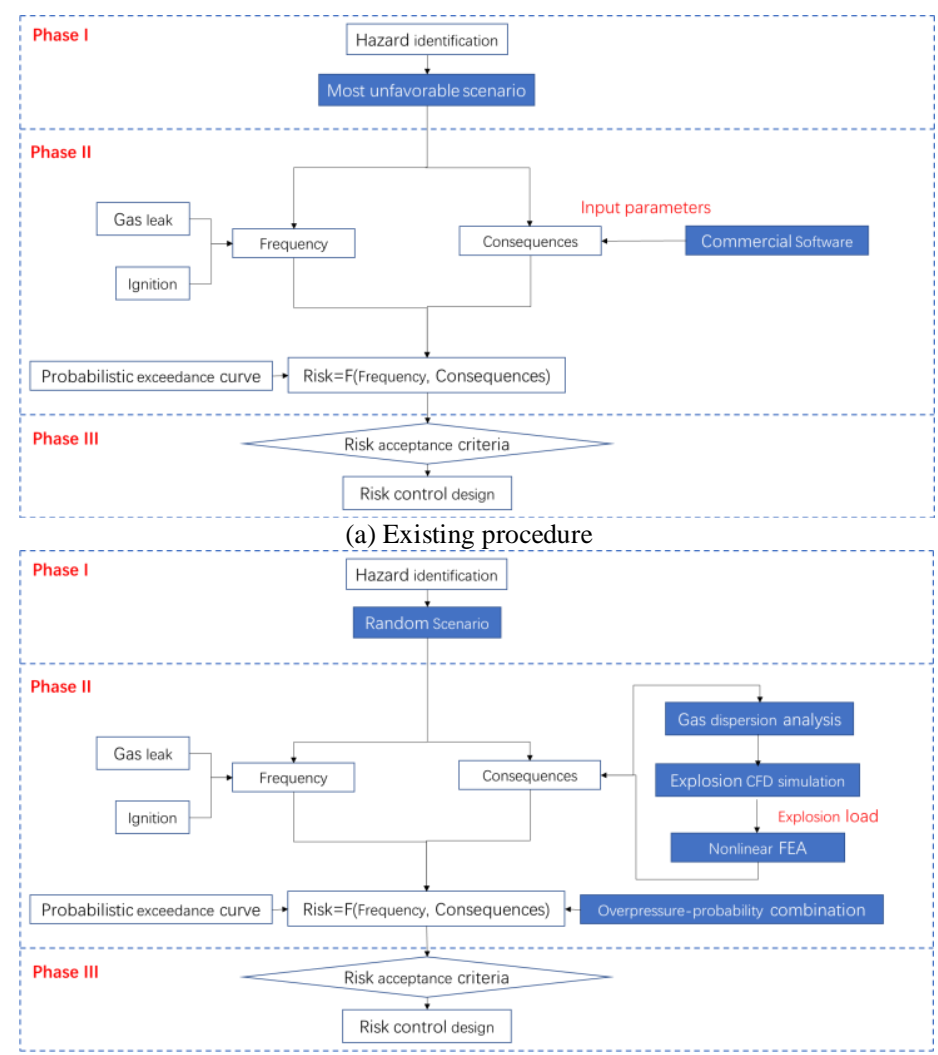

(b) Improved procedure

Fig. 1. The general procedure of QRA

(1) Phase I: identification of scenario

Selecting explosion scenarios starts with hazard identification based on a large database and provides important insights that help to define the parameters that affect explosions and to characterize the probability density functions of the influential parameters. A few unfavorable scenarios do not represent the physics of reality. Explosion scenarios should be selected realistically and represent all possible events.

Paik and Czujko [9] considered eight parameters, namely wind direction, wind speed, leak rate, leak duration, leak direction, leak position, in explosion scenario identification. Within those parameters, most variables can be calculated by collating historical databases. However, there is still no standardized procedure for the probabilistic determination of leak position and direction because both of them have strong inherent randomness. In this study, a method for determining leak position and direction, presented in Section 4, is further developed.

(2) Phase II: quantitative risk assessment

Gas explosion accidents can evolve from flammable gas leak, dispersion, ignition to explosion. The procedure identifies gas dispersion to determine the gas cloud characteristics associated with gas leaks. Explosion load analysis is subsequently undertaken based on the gas cloud information. The actual pressure loads are directly applied to the nonlinear structural analysis using the interface between CFD and the finite element model. Calculating the explosion risk requires the explosion frequency and related consequences to be defined. The explosion frequency is defined as the product of leak frequency and ignition probability.

The main goal of risk assessment is to determine design loads. 
At present, the most popular method for determining design loads is the probabilistic exceedance curve. However, this method has some limitations in some applications. The combination of overpressure and probability method is adopted in Section 5.3 based on the definition of risk.

(3) Phase III: risk control

Acceptance criteria are applied to determine whether it is necessary to take preventive measures. If the calculated risk exceeds an acceptable risk level, the system must be redesigned and/or risk control options, such as blast walls or blast partitions (decks), must be adopted.

\section{Target structure}

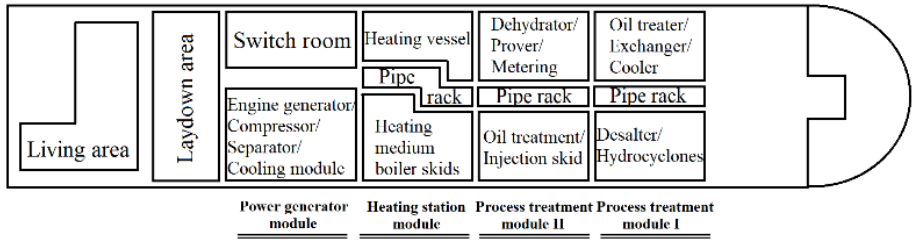

Fig. 2. The layout of the target structure

It is widely recognized that FPSO is a popular choice for oilfield development due to its huge advantage in low cost, wide suitability and huge oil storage, and discharge ability. Comparing with other forms of oil production platforms, FPSO shows various characteristics like high input, high risk, and high profit. Therefore, risk and reliability evaluation research of FPSO is very essential.

In this study, an authentic topside module of FPSO is selected as a target structure for an applied example including the selection of gas dispersion scenarios, probability analysis, consequence analysis, quantitative risk assessment. Fig. 2 presents the layout of the studied structure. It is mainly composed of four regions that are power generator module, heating station module, process treatment module II and process treatment module I.

Process treatment module I is arranged near the bow and is equipped with oil and gas processing important facilities such as crude oil thermal treater, crude oil heat exchangers, electric desalter, electric dehydrator. This module is the main area where crude oil is separated and processed after being input from the wellhead. This region is also a high-incidence area for oil and gas leakages and explosions in the topside model due to densely covered by the processing facilities. Furthermore, process treatment module II is assigned adjacent to process treatment module I, mainly consisting of processing and storage facilities, which is also a high-risk area for perils. Even if there are potential ignition points in the other two regions (power generator module and heating station module), the probability of oil and gas leakage and explosion is very low due to the sporadic distribution of processing facilities. Therefore, process treatment module I and II are selected for quantitative risk assessment based on the classification of locations for electrical installations with a risk of ignition [28].

\section{Selection of scenarios}

In gas explosions of structures and infrastructures, the characteristics of gas dispersion can be normally identified as a function of eight parameters, namely wind direction $\left(\mathrm{X}_{1}\right)$, wind speed $\left(\mathrm{X}_{2}\right)$, leak rate $\left(\mathrm{X}_{3}\right)$, leak duration $\left(\mathrm{X}_{4}\right)$, leak direction $\left(\mathrm{X}_{5}\right)$, leak position $\mathrm{X}\left(\mathrm{X}_{6}\right)$, leak position $\mathrm{Y}\left(\mathrm{X}_{7}\right)$, leak position $\mathrm{Z}\left(\mathrm{X}_{8}\right)$. Wind direction, wind speed, leak rate can be collated by the historical database, while leak direction and leak position are difficult to determine because of their randomness. If the leak position is determined randomly by three coordinates, the leak point may be selected on a non-leak facility. Given that leak location is closely related to which and where the device it is, this paper considers wind direction $\left(\mathrm{Y}_{1}\right)$, wind speed $\left(\mathrm{Y}_{2}\right)$, leak rate $\left(\mathrm{Y}_{3}\right)$, leak facility $\left(\mathrm{Y}_{4}\right)$, leak direction $\left(\mathrm{Y}_{5}\right)$, leak position $\mathrm{X}\left(\mathrm{Y}_{6}\right)$, leak position $\mathrm{Y}\left(\mathrm{Y}_{7}\right)$, leak position $\mathrm{Z}\left(\mathrm{Y}_{8}\right)$ in gas dispersion scenario selection.

Oil and gas processing and storage devices, such as crude oil thermal treater, crude daily tank, electric desalter, are prone to leakage accidents. Leak frequencies of the main facility in the FPSO topside are described in Table 1 according to the failure frequency guidance [29]. Assuming that the probability density in each interval is constant, probability density function and cumulative probability distribution function are obtained as shown in Eq. (1) and Eq. (2).

Table 1

Leak frequency of main facilities in FPSO topside module

\begin{tabular}{ccc}
\hline NO. & Facility & $\begin{array}{c}\text { Leak frequency } \\
\left(10^{-3} / \text { year }\right)\end{array}$ \\
\hline $0-1$ & Crude oil thermal treater & 2.36 \\
$1-2$ & Electric desalter & 2.36 \\
$2-3$ & Electric dehydrator pre-exchangers & 1.45 \\
$3-4$ & Spec oil/crude oil heat exchangers & 3.04 \\
$4-5$ & Electric dehydrator feed pumps & 6.53 \\
$5-6$ & Hydro cyclones & 2.05 \\
$6-7$ & Electric dehydrator & 2.36 \\
$7-8$ & Crude daily tank & 4.69 \\
$8-9$ & Fuel oil transfer pump & 6.53 \\
$9-10$ & Process pipeline & 0.43 \\
\hline
\end{tabular}

$f(x)=\left\{\begin{array}{c}0.074,0 \leq x<1 \\ 0.074,1 \leq x<2 \\ 0.046,2 \leq x<3 \\ 0.096,3 \leq x<4 \\ 0.205,4 \leq x<5 \\ 0.064,5 \leq x<6 \\ 0.074,6 \leq x<7 \\ 0.147,7 \leq x<8 \\ 0.205,8 \leq x<9 \\ 0.014,9 \leq x<10\end{array}\right.$

$P=F(x)=\left\{\begin{array}{c}0.074 x, 0 \leq x<1 \\ 0.074+0.074(x-1), 1 \leq x<2 \\ 0.148+0.046(x-2), 2 \leq x<3 \\ 0.194+0.096(x-3), 3 \leq x<4 \\ 0.290+0.205(x-4), 4 \leq x<5 \\ 0.495+0.064(x-5), 5 \leq x<6 \\ 0.559+0.074(x-6), 6 \leq x<7 \\ 0.634+0.147(x-7), 7 \leq x<8 \\ 0.781+0.205(x-8), 8 \leq x<9 \\ 0.986+0.014(x-9), 9 \leq x<10\end{array}\right.$ 
Eq. (3) is used to define the leak direction.

$S(x)=\left\{\begin{array}{c}1,0 \leq x-[x]<0.167 \\ 2,0.167 \leq x-[x]<0.334 \\ 3,0.334 \leq x-[x]<0.501 \\ 4,0.501 \leq x-[x]<0.668 \\ 5,0.668 \leq x-[x]<0.835 \\ 6,0.835 \leq x-[x]<1.00\end{array}\right.$

Where $x$ represents the number of facilities. $S(x)=1,2,3,4,5,6$ represents the leakage position is at the midpoint of the corresponding (left, right, front, back, down, up) surface along corresponding $(-\mathrm{x},+\mathrm{x},-\mathrm{y},+\mathrm{y},-\mathrm{z},+\mathrm{z})$ axis. For example, if the random variable is 7.16 , it represents that the leakage device is the crude daily tank and the leakage position is at the midpoint of the left surface along - $\mathrm{x}$ axis.

Based on the probability density functions defined in Eq. (1) and Figs. 3-5, scenarios for the gas dispersion analysis can be selected by sampling techniques. Latin hypercube sampling (LHS) is one of such techniques that can obtain a reasonable distribution covering all variables even with a small sample number. The form of the LHS method adopted in this paper is shown in Eq. (4).

$x_{i}=F^{-1}\left(\frac{m_{i}-0.5}{N}\right)$

Where $N$ represents sample number, $m_{i}$ represents the $i$ th item in the sample, and $F^{-1}$ is the inverse function of the cumulative probability distribution.

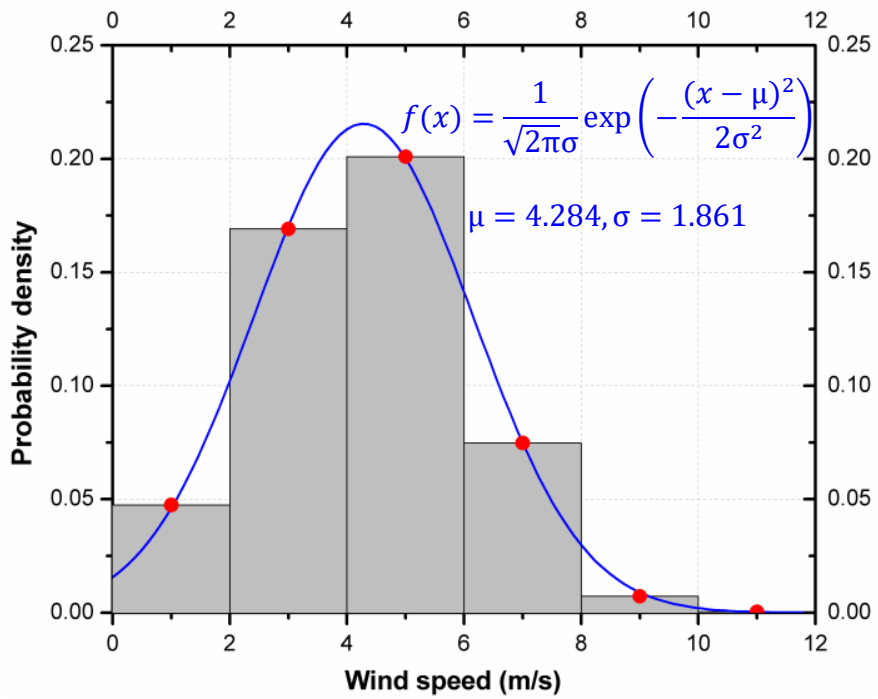

(a)

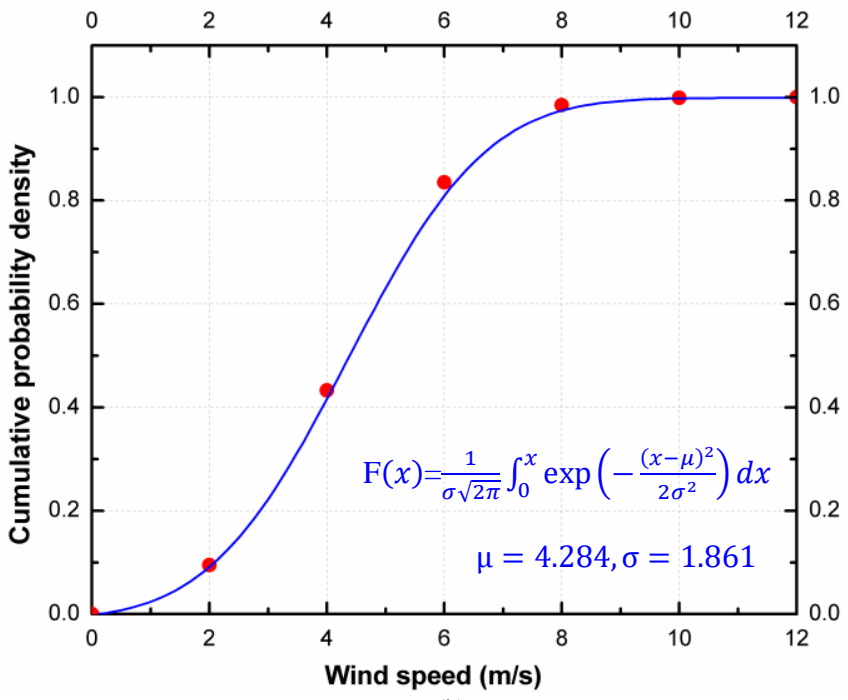

(b)

Fig. 3. Probability density function and cumulative probability density function of wind speed
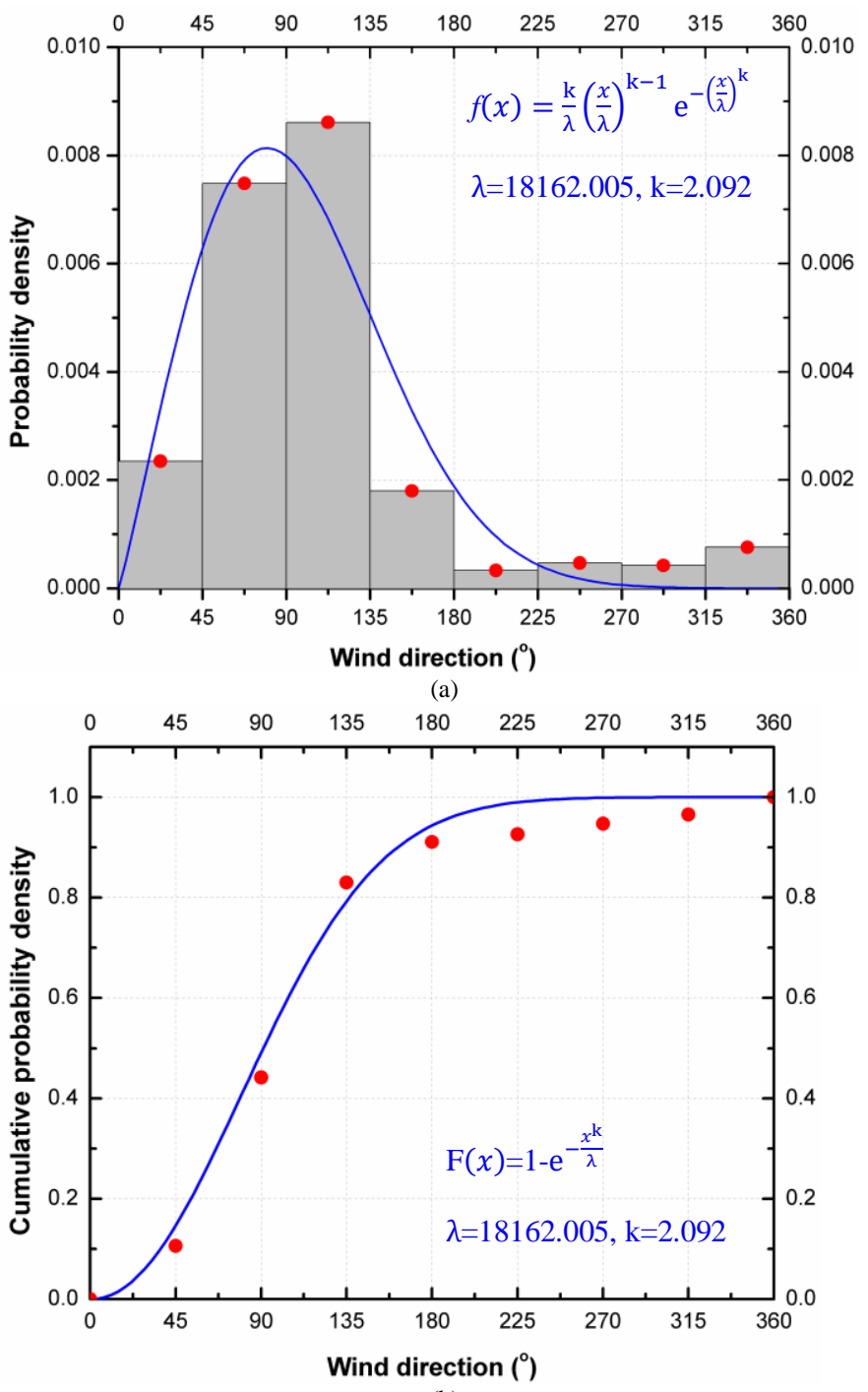

(b)

Fig. 4. Probability density function and cumulative probability density function of wind direction 

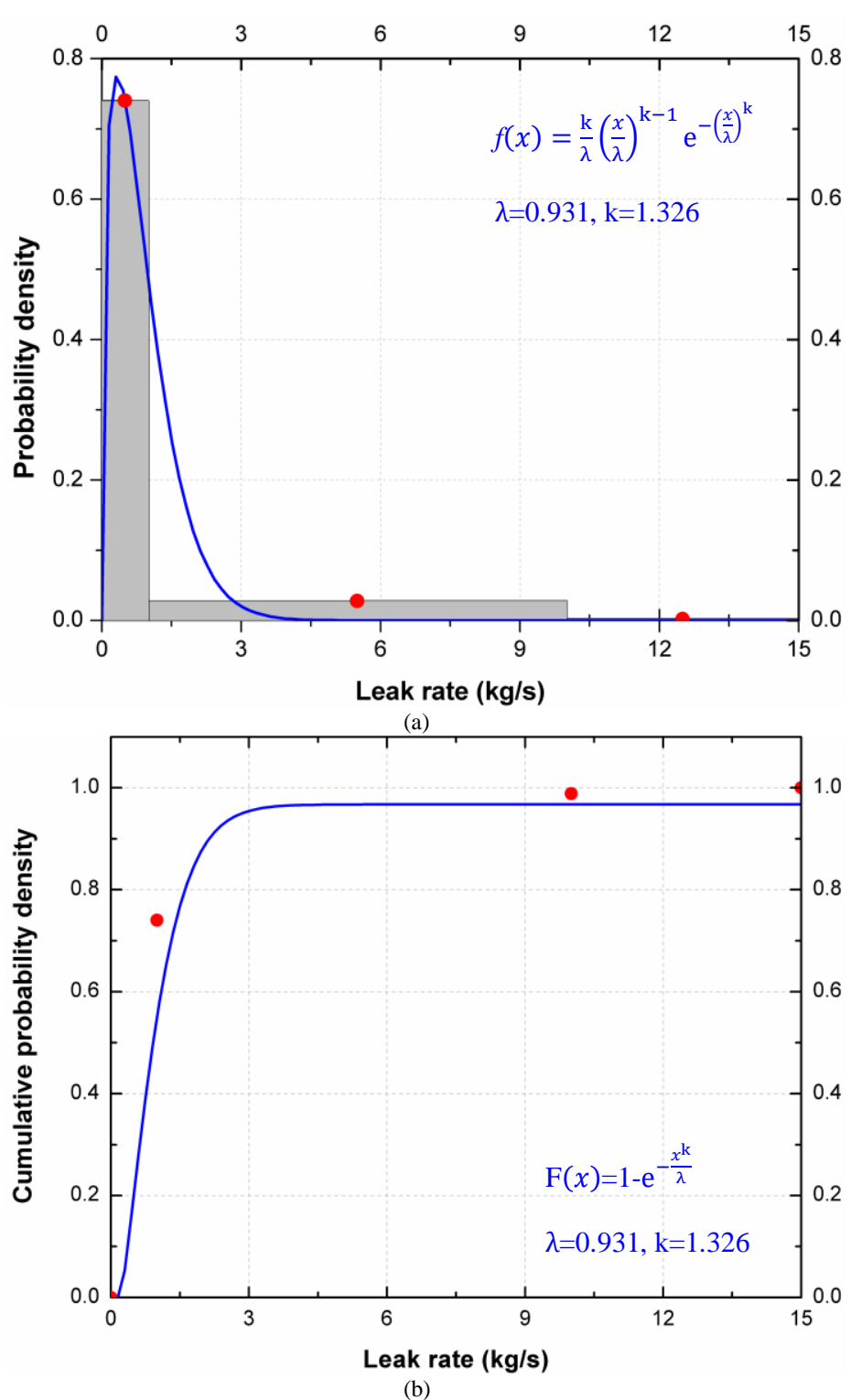

Fig. 5. Probability density function and cumulative probability density function of leak rate

Completed by MATLAB, the sampling results of eight variables can be generated. A total of 60 selected scenarios are presented in Table A.1.

\section{Quantitative risk assessment}

\subsection{Probability analysis}

An explosion event occurs after a period of the gas leak when it reaches the explosive limit. Gas explosions cannot occur without ignition even in the event of flammable gas or oil leak. The frequency of gas explosions can be calculated as follows [9].

$F_{\text {explosion }}=F_{\text {leak }} \times P_{\text {ignition }}$

Where $F_{\text {leak }}$ represents the leak frequency and $P_{\text {ignition }}$ represents the ignition probability.

The leak frequency can be determined by Table 1 . The ignition probability is positively correlated with the leak rate [30]. The total ignition probability presented can be considered as the sum of the probabilities of immediate ignition and delayed ignition. Table A.2 shows the explosion probabilities of the selected scenarios.

\subsection{Consequence analysis}

Consequence analysis involves the equivalent gas cloud in leak simulation and the overpressure distribution caused by gas explosions. The flow chart of consequence analysis can be described as follow.

(1) The equivalent gas cloud volume of each scenario is obtained by performing gas dispersion simulation.

(2) Evaluate the important influence parameters of explosion overpressure, especially the arrangement of the equivalent gas cloud and ignition position, to get reasonable explosion scenarios.

(3) The maximum and average values of explosion overpressure in different areas can be obtained by explosion simulations. Then assets and personnel damages can be evaluated.

\subsubsection{Modeling}

Gas explosions are the phenomenon of a sharp increase in pressure caused by the combustion of premixed gases, which can be divided into three categories: explosion in confined space, semiconfined space and unconfined space. Explosion overpressures in the above three situations are quite different. Despite the FPSO topside model used in this paper can be regarded as the unconfined space, production, storage equipment, and various pipelines are densely packed on the deck. Therefore, immeasurable damage could happen once the explosion occurs.

In the leakage model, the external ventilation direction and non-ventilation direction adopt WIND and NOZZLE boundary conditions, respectively. Based on the results of the grid independence test, multiple-mesh geometry is adopted. $0.1 \mathrm{~m} \times 0.1$ $\mathrm{m} \times 0.1 \mathrm{~m}$ is chosen for the basic mesh size in the leak area, while mesh sizes in other simulation regions are enlarged accordingly. 1 $\mathrm{m} \times 1 \mathrm{~m} \times 1 \mathrm{~m}$ for the main structures, and then extends to the boundaries. Assuming that the flammable gas is composed of $84.9 \%$ methane, $10.5 \%$ ethane, $3.2 \%$ propane and $1.4 \%$ butane. Fig. 6 shows the grid in the CFD model.

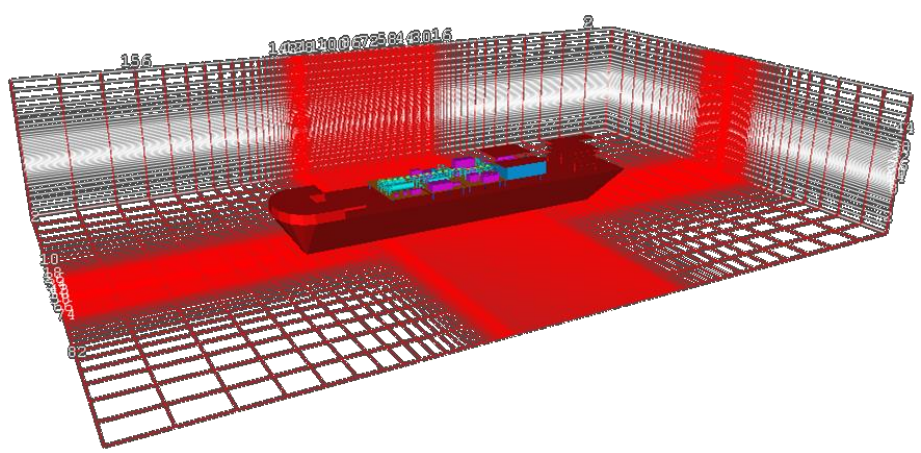

Fig. 6. Grid in the CFD model

\subsubsection{Dispersion}

The effect of the gas explosion strongly relies on the ignition time and location. Besides, whether mixed gas can be detonated is also related to the gas concentration. It is evident that gas 
concentration changes with times during the dispersion. Theoretically, there are still numerous explosion scenarios even if the gas dispersion scenarios are determined. However, it is found that the area covered by gas continuously increases and stays stably when gas dispersion is long enough [31].

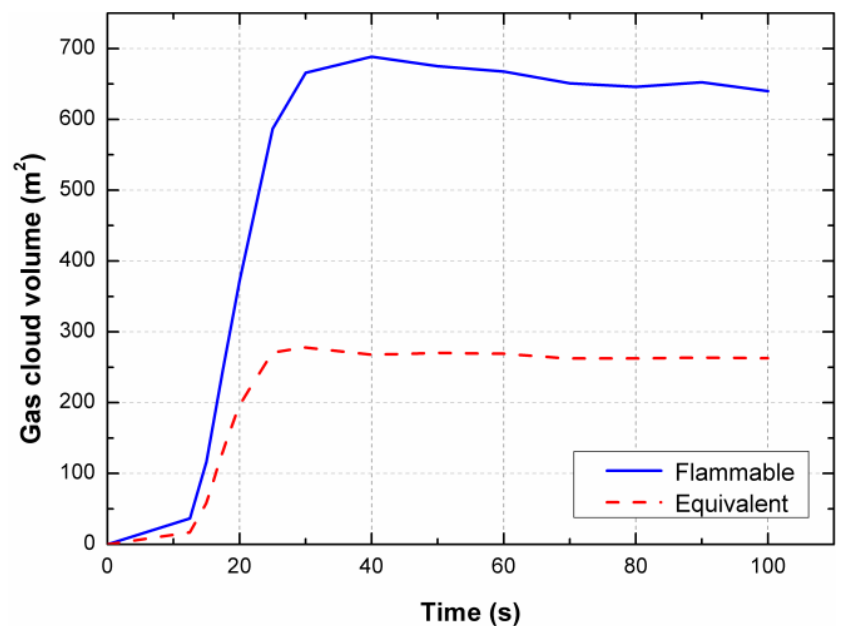

Fig. 7. The relation between flammable and equivalent gas cloud volumes

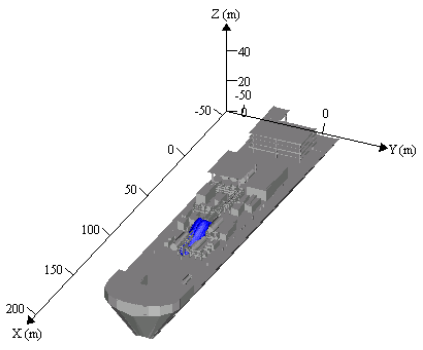

(a) $\mathrm{T}=25 \mathrm{~s}$

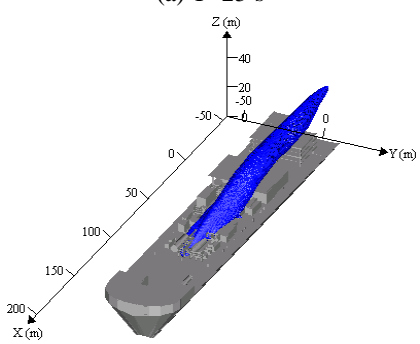

(c) $\mathrm{T}=75 \mathrm{~s}$

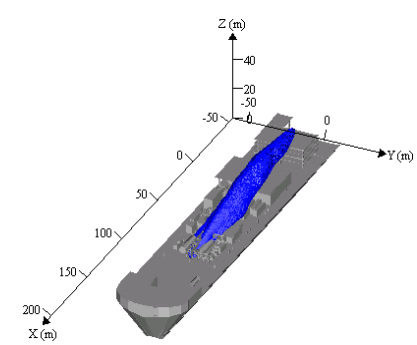

(b) $\mathrm{T}=50 \mathrm{~s}$

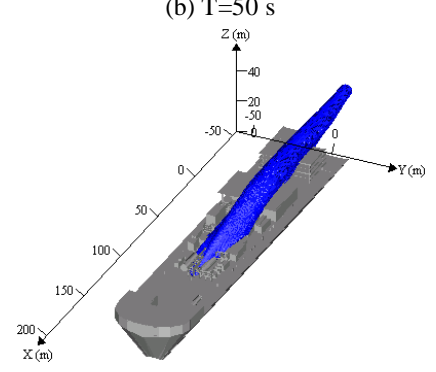

(d) $\mathrm{T}=100 \mathrm{~s}$
Fig. 8. Gas cloud at different times

An equivalent stoichiometric gas cloud with comparable explosion consequences is employed to estimate the natural gas to evaluate the hazard of a given gas cloud. Flammable gas volume refers to the volume occupied by the gas concentration within the burning limit at a certain moment. The equivalent gas cloud converts the gas with an uneven distribution of actual gas concentration into a uniformly distributed gas concentration. The two parameters reflect the same law as the area covered by the flammable gas. As can be seen in Fig. 7, both flammable and equivalent gas cloud volumes reach peak values and then keep stable. Moreover, the buoyancy effect as shown in Fig. 8 will occur as far as the effects of wind and ventilation are applied because methane is lighter than air.

The equivalent gas cloud is represented by a cuboid in explosion simulation. In the present illustrative example, gas cloud volumes in $100 \mathrm{~s}$ are applied in the following explosion analysis. As the equivalent gas cloud should cover as large as possible with the actual gas cloud. The following methods are used to determine the equivalent gas cloud size and location.

(1) The initial gas cloud size and location are defined by Eq. (6) and Fig. 9.

$\mathrm{L}_{\mathrm{X}}=\mathrm{L}_{\mathrm{Y}}=\mathrm{L}_{\mathrm{Z}}=\mathrm{V}_{\text {equivalent }}^{1 / 3}$

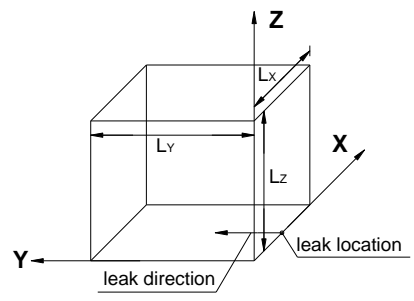

(a)

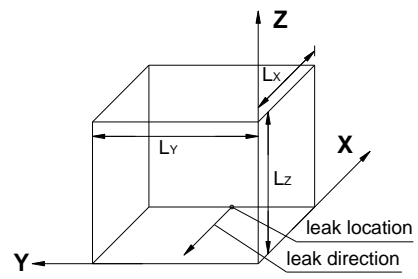

(c)

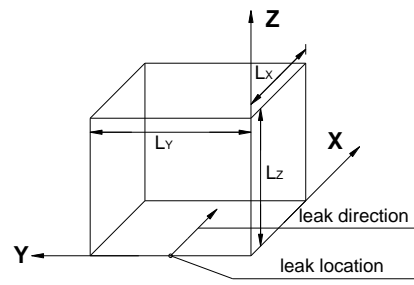

(e)

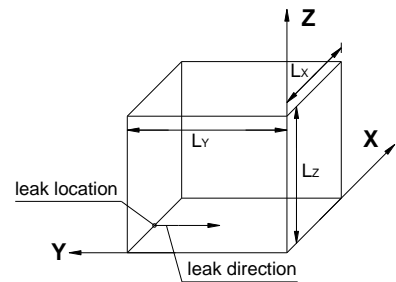

(b)

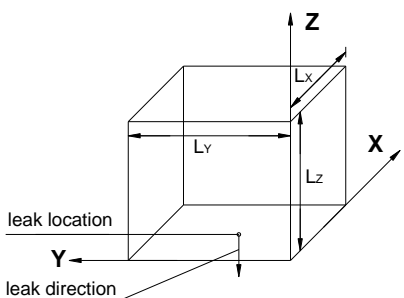

(d)

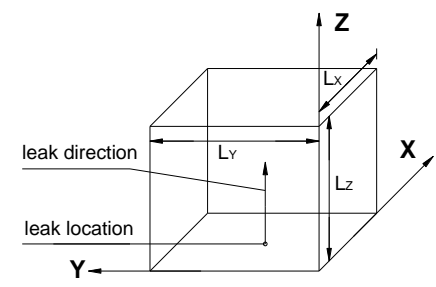

(f)
Fig. 9. Initial location and geometry of the equivalent gas cloud

(2) When $L_{Z} \leq S_{Z}$, move the part beyond the structural boundary into the studied structure if the lateral boundary of the cuboid exceeds the structural boundary, as shown in Fig. 10(a).

(3) When $L_{Z}>S_{Z}$, the position and size of the equivalent gas cloud depend on the size of the structure in the $\mathrm{X}$ and $\mathrm{Y}$ directions, as shown in Fig. 10(b).

If $\mathrm{V}_{\text {equivalent }} / \mathrm{S}_{\mathrm{Z}}<\mathrm{S}_{\mathrm{X}}^{2}$ (assuming $\mathrm{S}_{\mathrm{X}}<\mathrm{S}_{\mathrm{Y}}$ ), then define $\mathrm{L}_{\mathrm{Z}}^{\prime}=\mathrm{S}_{\mathrm{Z}}, \mathrm{L}_{\mathrm{X}}^{\prime}=\mathrm{L}_{\mathrm{Y}}^{\prime}=\left(\mathrm{V}_{\text {equivalent }} / \mathrm{S}_{\mathrm{Z}}\right)^{1 / 2}$. Move the part beyond the structural boundary into the studied structure if the lateral boundary of the cuboid exceeds the structural boundary.

If $\mathrm{S}_{\mathrm{X}}^{2} \leq \mathrm{V}_{\text {equivalent }} / \mathrm{S}_{\mathrm{Z}}<\mathrm{S}_{\mathrm{X}} * \mathrm{~S}_{\mathrm{Y}}$, then define $\mathrm{L}_{\mathrm{Z}}^{\prime}=\mathrm{S}_{\mathrm{Z}}, \mathrm{L}_{\mathrm{X}}^{\prime}=$ $\mathrm{S}_{\mathrm{X}}, \mathrm{S}_{\mathrm{Y}}=\mathrm{V}_{\text {equivalent }} /\left(\mathrm{S}_{\mathrm{X}} * \mathrm{~S}_{\mathrm{Z}}\right)$. Move the part beyond the structural boundary into the studied structure if the lateral boundary of the cuboid exceeds the structural boundary.

If $\mathrm{S}_{\mathrm{X}} * \mathrm{~S}_{\mathrm{Y}} \leq \mathrm{V}_{\text {equivalent }} / \mathrm{S}_{\mathrm{Z}}$, then define $\mathrm{L}_{\mathrm{X}}^{\prime}=\mathrm{S}_{\mathrm{X}}, \mathrm{L}_{\mathrm{Y}}^{\prime}=\mathrm{S}_{\mathrm{Y}}$, $\mathrm{S}_{\mathrm{Z}}=\mathrm{V}_{\text {equivalent }} /\left(\mathrm{S}_{\mathrm{X}} * \mathrm{~S}_{\mathrm{Y}}\right)$. 


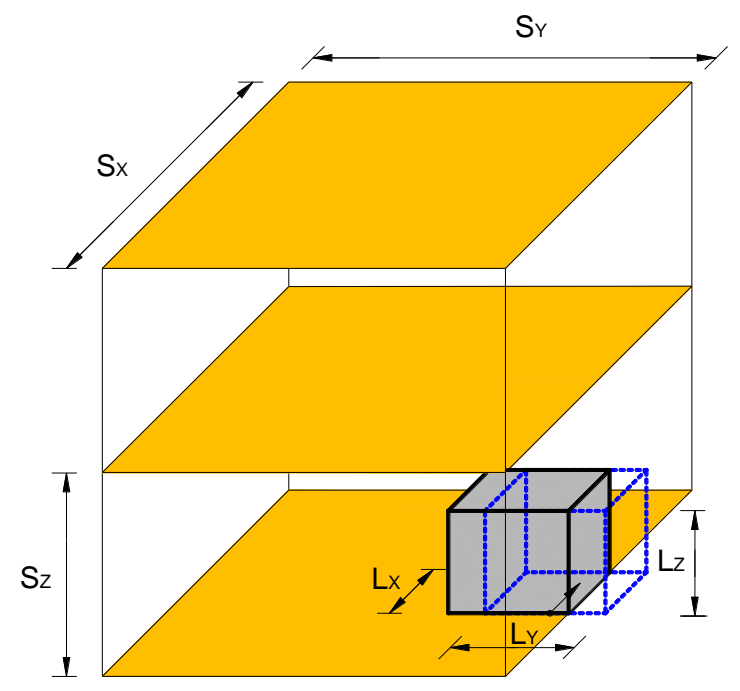

(a)

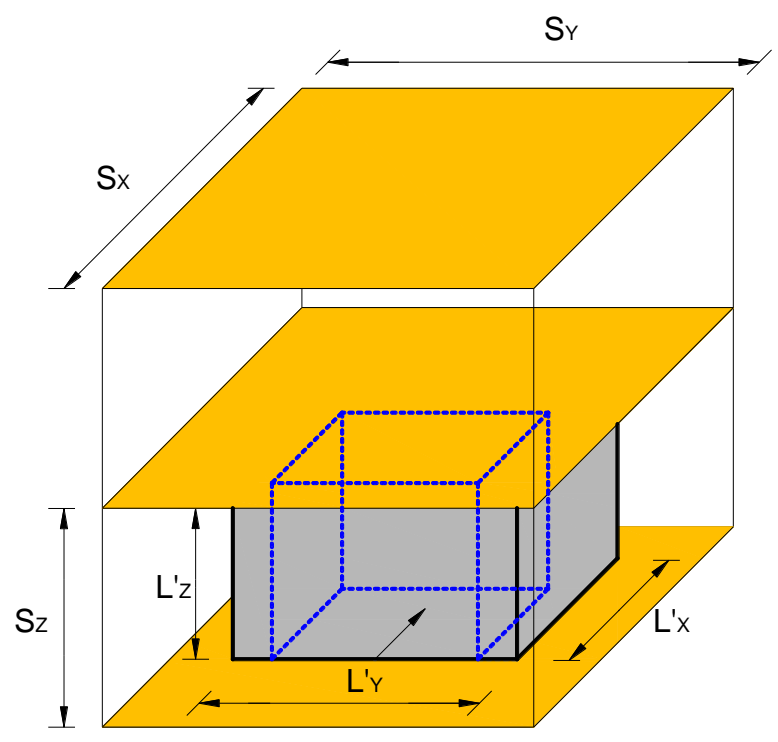

(b)

Fig. 10. Example of gas cloud position determination

Thus, the equivalent gas cloud can be located inside the leakage floor as much as possible and basically in the area above the leak point. The ignition is set to the center of the cuboid.

\subsubsection{Explosion}

Oil and gas transmission pipelines are established in the middle of the two process modules, subdividing the two regions into two parts in the same size. As seen in Fig. 11, four studied areas are formed.

Two kinds of monitoring surfaces are used to obtain maximum and average overpressures. Maximum overpressure is calculated by comparing values acquired from $2 \mathrm{~m} \times 2 \mathrm{~m} \times 0 \mathrm{~m}$, while average overpressure is achieved by $24 \mathrm{~m} \times 18 \mathrm{~m} \times 0 \mathrm{~m}$. Fig. 12 gives an example of the monitoring arrangement. The ignition point is placed near the center of the equivalent gas cloud to avoid conflicts with structures and grids. Fig. 13 shows the maximum and average overpressure in selected scenarios, which are the results of explosion simulations.

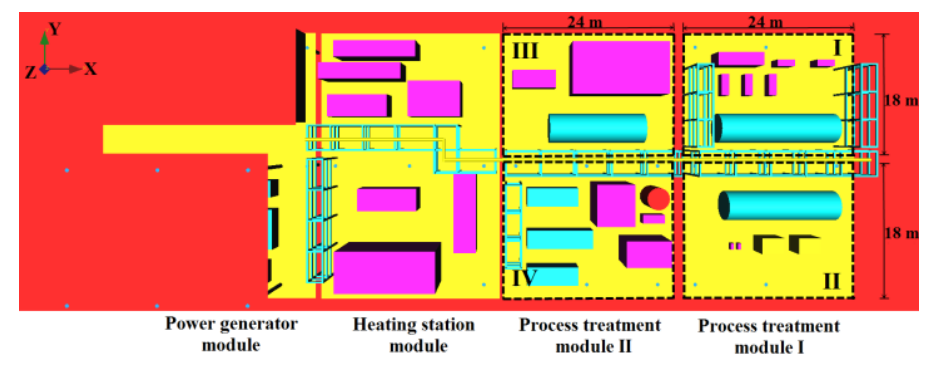

Fig. 11. The studied area in quantitative risk assessment

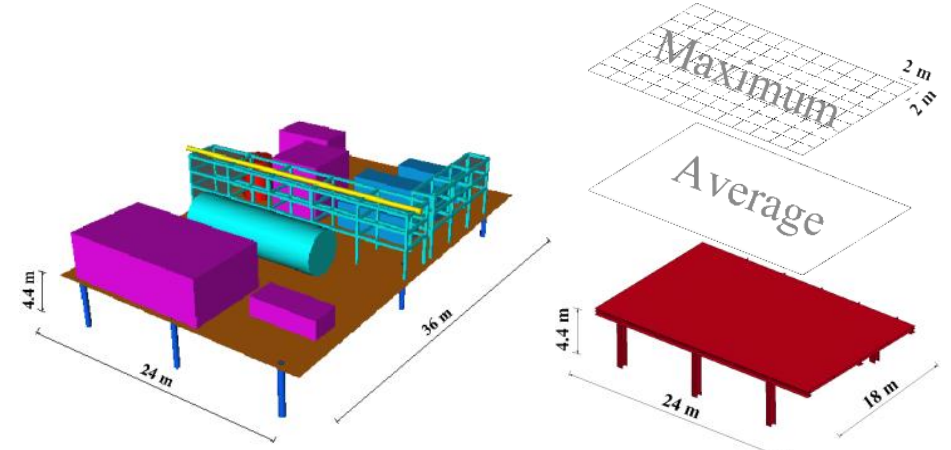

Fig. 12. Process treatment model and deck model

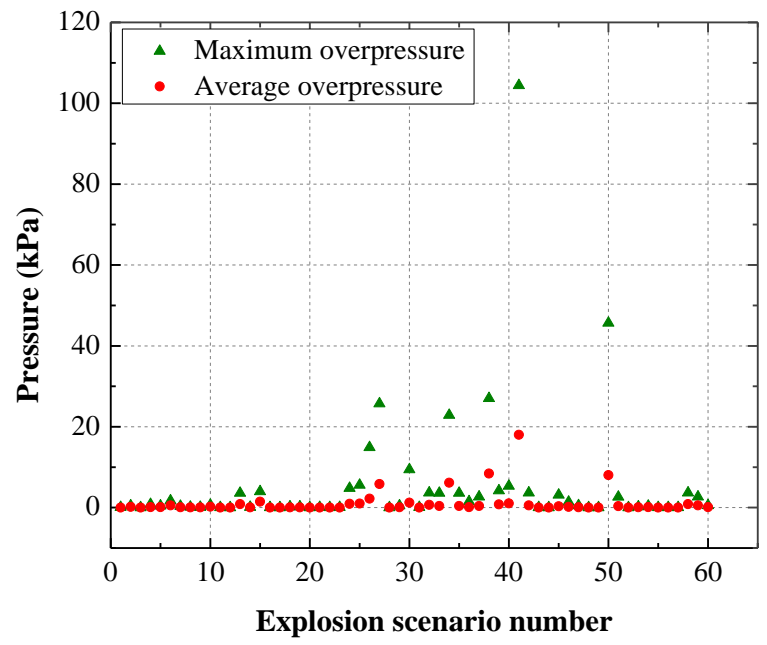

(a) Region I

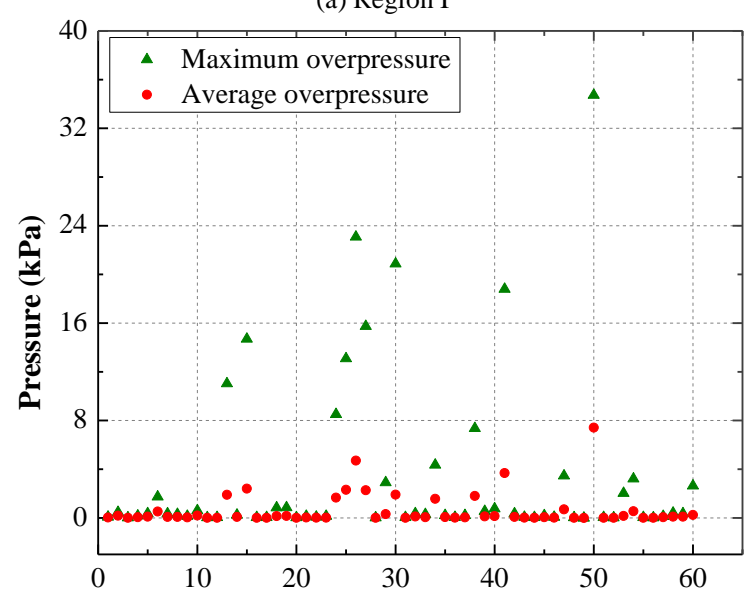

Explosion scenario number

(b) Region II 


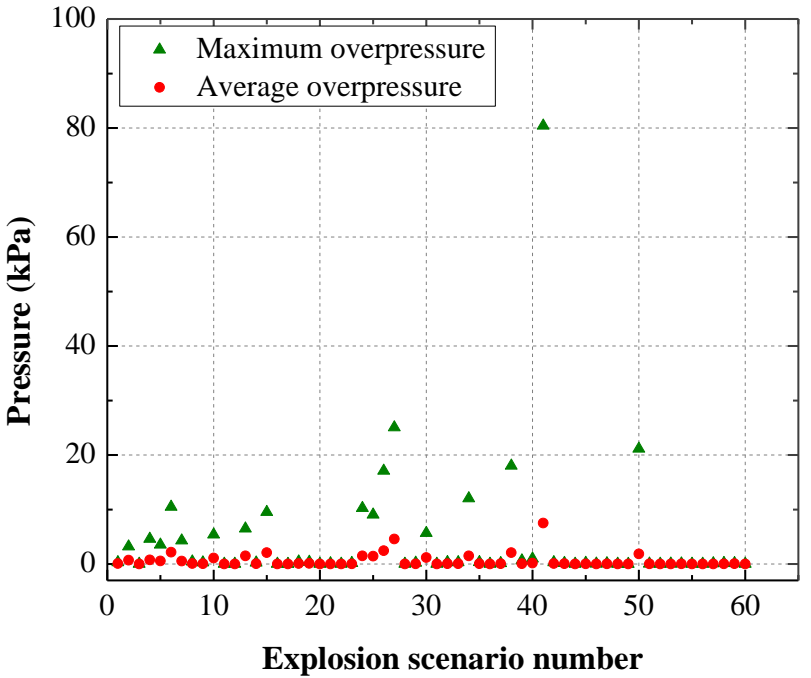

(c) Region III

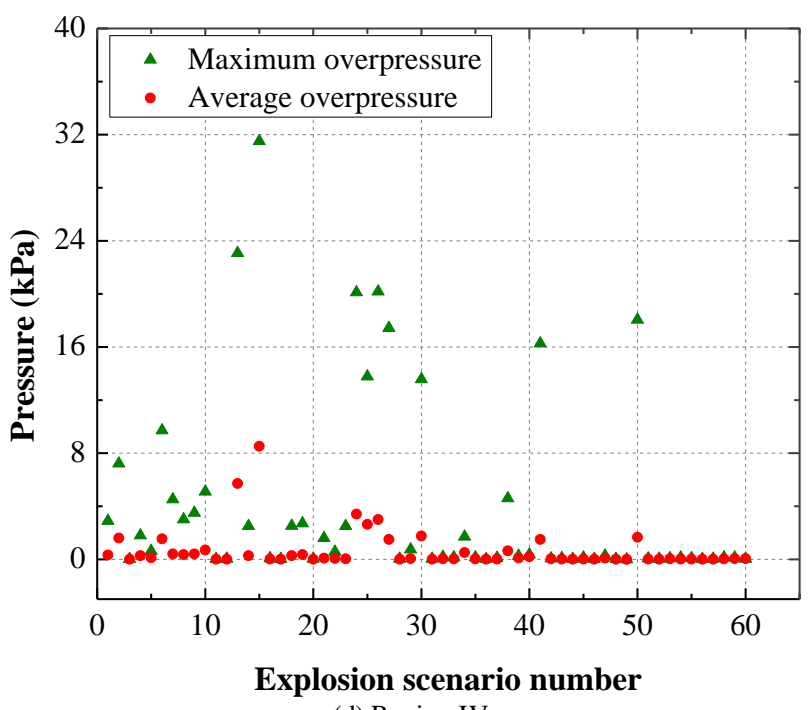

(d) Region IV

Fig. 13. Results of explosion simulations

\subsection{Quantitative risk assessment}

The most common method for quantitative risk assessment is using probability exceedance curves to determine the design values of explosion loads. This method is useful in determining the nominal values of safety design and engineering for structural systems. Refined computations and physical model testing for each scenario selected are used to characterize the physical parameters as actions or action effects in advance. However, if a criterion is set before the analysis is performed, the focus will naturally be on indicating that the risk is below this criterion and that potential risk mitigation measures may be ignored [32]. Moreover, there probably will be a non-existent equivalent design scenario for the 3D spatial scalar variables [14] or the exceedance curves may not reach the design criterion especially when the scenario number is small. Fig. 14 demonstrates the above two situations.

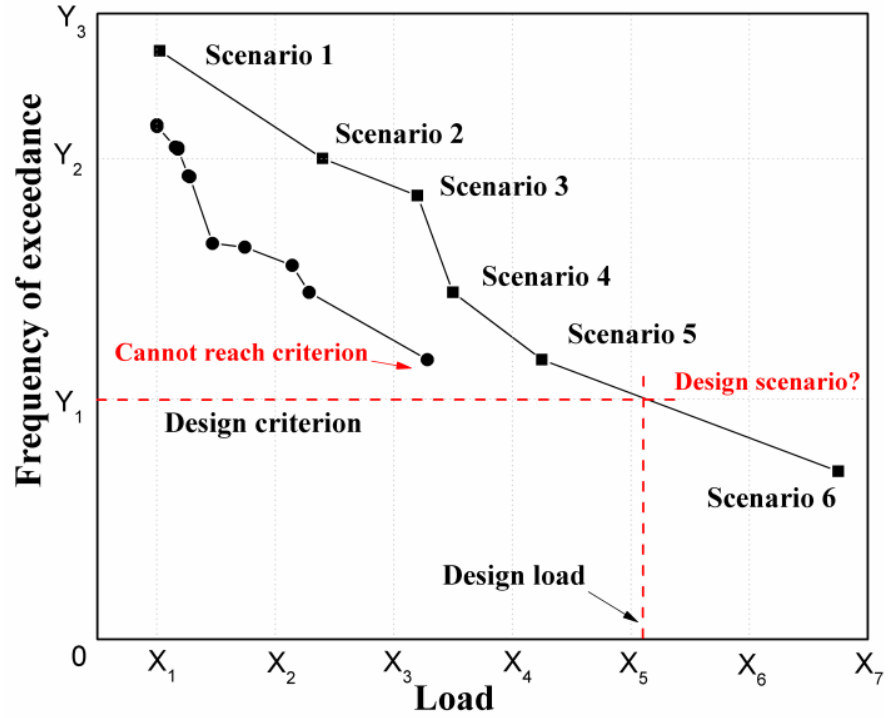

Fig. 14. Example of two invalid situations

\subsubsection{Probability exceedance diagrams}

The explosion loads and structural consequences are combined with consequence probability in probability exceedance diagrams. Overpressure is generally used for the design parameter in explosions and is used for defining the evaluation results on personnel, assets, and environment. The overpressure-probability curve refers to the probability that the explosion overpressure exceeds a certain pressure value in all explosion scenarios. The acceptable frequency of exceedance of the severity of the design or dimensioning scenarios is typical of the order of $10^{-4}$ per year. Table 3 gives the maximum and average designed overpressures.

Table 3

Maximum and average designed overpressures in different regions $(\mathrm{kPa})$

\begin{tabular}{ccccc}
\hline Region & I & II & III & IV \\
\hline Maximum designed overpressure & 101.87 & 25.80 & 72.55 & 31.10 \\
\hline Average designed overpressure & 17.86 & 5.34 & 7.17 & 8.38 \\
\hline
\end{tabular}

\subsubsection{Overpressure-probability combination}

The probability exceedance method can intuitively establish the relationship between the consequences and probabilities. However, it is difficult to meet the acceptance criterion (that is, $10^{-4}$ per year) if the number of samples is small. Sometimes researchers have to increase the sampling number or adjust the porosity of the whole structure to find proper values that meet the acceptance criterion.

In practical engineering, some accidents may have unpredictable consequences but with low probability. On the contrary, some accidents have high probabilities, but the consequences are not harmful to the essentials. Therefore, the risk of an accident is related to both probability and consequences. This paper gives an improved method for risk assessment of explosions based on the definition of risk. Eq. (7) shows the expression of the proposed method. 


$$
R_{i}=\sum_{j}\left(C_{i j} \times P_{i j}\right)
$$

where $C_{i j}$ is the overpressure generated for the scenario $j$ in $i$ region, and $P_{i j}$ is the explosion probability of the scenario $j$.

Table 4 shows the maximum overpressure-probability in different regions. It turns out that the probability exceedance method and overpressure-probability combination method reveal good consistency: risks of region I and III are larger than those of region II and IV. The results prove the validity of the proposed method.

Table 4

Overpressure-probability in different regions

\begin{tabular}{|c|c|c|c|c|}
\hline Region & I & II & III & IV \\
\hline Overpressure-probability & 22.46 & 14.78 & 19.67 & 17.09 \\
\hline
\end{tabular}

\section{Risk evaluation}

Book [33] gives methods for the determination of possible damage to people and assets resulting from releases of hazardous materials. The acceptable criterion for the overpressure of the personnel and structure can be summarized as Table 5 and Table 6.

Table 5

Explosion damages on personnel $(\mathrm{kPa})$

\begin{tabular}{cc}
\hline Overpressure & Damage \\
\hline$>100$ & Dead \\
$50-100$ & Serious injury \\
$30-50$ & Moderate injury \\
$7-30$ & Minor injury \\
\hline
\end{tabular}

Table 6

Explosion damages on structure $(\mathrm{kPa})$

\begin{tabular}{cc}
\hline Overpressure & Damage \\
\hline$>40$ & Severe damage in steel \\
$30-40$ & Damage in concrete frame \\
$20-30$ & Oil tank, pipeline rupture \\
$15-20$ & Glass in the window facing pressure broken \\
$8-15$ & Wire-fixed glass broken \\
$3-8$ & Glass window damage \\
\hline
\end{tabular}

Table 7

Risk assessment of casualties in different regions $\left(10^{-5}\right)$

\begin{tabular}{ccccc}
\hline Region & I & II & III & IV \\
\hline Probability of dead & 9.80 & 0 & 0 & 0 \\
$\begin{array}{c}\text { Probability of serious injury or above } \\
\begin{array}{c}\text { Probability of moderate injury or } \\
\text { above }\end{array}\end{array}$ & 9.80 & 0 & 9.80 & 0 \\
$\begin{array}{c}\text { Probability of minor injury or above } \\
\text { (4).54 }\end{array}$ & 44.33 & 96.87 & 98.18 & 96.23 \\
\hline
\end{tabular}

Table 8

Risk assessment of structural damage in different regions $\left(10^{-5}\right)$

\begin{tabular}{ccccc}
\hline Region & I & II & III & IV \\
\hline $\begin{array}{c}\text { Probability of severe damage } \\
\text { in steel }\end{array}$ & 14.54 & 0 & 9.80 & 0 \\
$\begin{array}{c}\text { Probability of damage in } \\
\text { concrete frame }\end{array}$ & 14.54 & 4.74 & 9.80 & 9.63 \\
$\begin{array}{c}\text { Probability of oil tank, } \\
\text { pipeline rupture }\end{array}$ & 35.89 & 13.18 & 15.98 & 28.05 \\
$\begin{array}{c}\text { Probability of glass in the } \\
\text { window facing pressure } \\
\text { broken }\end{array}$ & 35.89 & 24.42 & 34.59 & 44.02 \\
$\begin{array}{c}\text { Probability of wired-fixed } \\
\text { glass broken }\end{array}$ & 44.33 & 85.11 & 98.18 & 87.22 \\
$\begin{array}{c}\text { Probability of glass window } \\
\text { damage }\end{array}$ & 111.56 & 105.56 & 117.88 & 110.33 \\
\hline
\end{tabular}

According to the damage degree caused by different overpressures on personnel and assets, probabilities of casualties and structural damage in four regions are presented in Table 7 and Table 8. In general, the probabilities of death directly caused by overpressures are pretty low. It should be noticed that region I and III are dangerous areas where staff should pay more attention when working.

\section{Conclusions}

An improved method for quantitative risk assessment of unconfined offshore installations subjected to gas explosions is proposed in this paper.

(1) Based on the stochastic sampling method, different affecting parameters are considered in this paper. Leak facilities are determined firstly, then leak position can be obtained by combing the leak facility and leak direction. This method not only ensures that the leak points are located on the corresponding facilities but also reduces calculation costs.

(2) Flammable gas leakage, dispersion and explosion are studied in CFD simulation where the method for determining the equivalent gas cloud position is demonstrated.

(3) Quantitative risk assessment combines the probabilities and consequences by both probability exceedance curves and the overpressure-probability method. For some situations that probability exceedance curves cannot be applicable, the overpressure-probability method can be used to evaluate the risk to assets for damage consequence.

More accurate results can be obtained by the proposed method. These advantages have been illustrated by the example presented in this paper.

\section{Acknowledgments}

One of the authors (Y. Xu) expresses her gratitude to the joint Ph.D. program (CSC NO.201806320085) of the China Scholarship Council for finical support. 


\section{References}

[1] Veritas DN. Accident statistics for floating offshore units on the UK Continental Shelf 1980-2005. Health and Safety Executive (HSE) Report 2007.

[2] Spouge J. A Guide to Quantitative Risk Assessment for Offshore Installations. DNV Tech 1999. https://doi.org/ISBN I 870553365.

[3] Paik JK, Czujko J. Assessment of hydrocarbon explosion and fire risks in offshore installations: Recent advances and future trends. IES J Part A Civ Struct Eng 2011. https://doi.org/10.1080/19373260.2011.593345.

[4] Azzi C, Rogstadkjernet L, van Wingerden K, Choi J, Ryu Y. Influence of scenario choices when performing CFD simulations for explosion risk analyses: Focus on dispersion. J Loss Prev Process Ind 2016. https://doi.org/10.1016/j.jlp.2016.03.012.

[5] Kim SJ, Lee DH, Hong HM, Ahn SH, Park JB, Seo JK, et al. Methods for determining the optimal arrangement of water deluge systems on offshore installations. Ocean Eng 2016. https://doi.org/10.1016/j.oceaneng.2016.01.010.

[6] Kim SJ, Kim BJ, Seo JK, Paik JK. A New Method for Structural Assessment of Topside Structure Subjected to Hydrocarbon Explosions. Procedia Eng., 2017. https://doi.org/10.1016/j.proeng.2016.12.067.

[7] API. Recommended Practice for Planning, Designing and Constructing Fixed Offshore Platforms - Working Stress Design. Api Recomm 2007. https://doi.org/10.1007/s13398-014-0173-7.2.

[8] Fire and explosion guidance. UKOOA/HSE 2007.

[9] Paik JK, Czujko J, Kim BJ, Seo JK, Ryu HS, Ha YC, et al. Quantitative assessment of hydrocarbon explosion and fire risks in offshore installations. Mar Struct 2011. https://doi.org/10.1016/j.marstruc.2011.02.002.

[10] Sohn JM, Kim SJ, Kim BH, Paik JK. Nonlinear structural consequence analysis of FPSO topside blast walls. Ocean Eng 2013. https://doi.org/10.1016/j.oceaneng.2012.12.005.

[11] Hansen OR, Kjellander MT, Martini R, Pappas JA. Estimation of explosion loading on small and medium sized equipment from CFD simulations. J Loss Prev Process Ind 2016. https://doi.org/10.1016/j.jlp.2015.12.004.

[12] Kang KY, Choi KH, Choi J, Ryu Y, Lee JM. Dynamic response of structural models according to characteristics of gas explosion on topside platform. Ocean Eng 2016. https://doi.org/10.1016/j.oceaneng.2015.12.043.

[13] Syed ZI, Mohamed OA, Rahman SA. Non-linear Finite Element Analysis of Offshore Stainless Steel Blast Wall under High Impulsive Pressure Loads. Procedia Eng., 2016. https://doi.org/10.1016/j.proeng.2016.04.164.

[14] Jin Y, Jang BS. Probabilistic fire risk analysis and structural safety assessment of FPSO topside module. Ocean Eng 2015. https://doi.org/10.1016/j.oceaneng.2015.04.019.

[15] Huang Y, Ma G, Li J. Multi-level explosion risk analysis (MLERA) for accidental gas explosion events in super-large FLNG facilities. J Loss Prev Process Ind 2017. https://doi.org/10.1016/j.jlp.2016.11.004.

[16] Chen GH, Liang T, Zhang H, Yan WW, Chen QG. Quantitative risk assessment of liquefied chlorine leakage accident via SAFETI. Huanan Ligong Daxue Xuebao/Journal
South China Univ Technol (Natural Sci 2006.

[17] Dan S, Lee CJ, Park J, Shin D, Yoon ES. Quantitative risk analysis of fire and explosion on the top-side LNGliquefaction process of LNG-FPSO. Process Saf Environ Prot 2014. https://doi.org/10.1016/j.psep.2014.04.011.

[18] Langdon GS, Schleyer GK. Response of quasi-statically loaded corrugated panels with partially restrained boundaries. Exp Mech 2007. https://doi.org/10.1007/s11340-006-9026-4.

[19] Bubbico R, Salzano E. Acoustic analysis of blast waves produced by rapid phase transition of LNG released on water. Saf Sci 2009. https://doi.org/10.1016/j.ssci.2008.07.033.

[20] Bae MH, Paik JK. Effects of structural congestion and surrounding obstacles on the overpressure loads in explosions: experiment and CFD simulations. Ships Offshore Struct 2018. https://doi.org/10.1080/17445302.2017.1347978.

[21] Gupta S, Chan S. A CFD based explosion risk analysis methodology using time varying release rates in dispersion simulations. J Loss Prev Process Ind 2016. https://doi.org/10.1016/j.jlp.2015.11.004.

[22] Sohn JM, Kim SJ, Seo JK, Kim BJ, Paik JK. Strength assessment of stiffened blast walls in offshore installations under explosions. Ships Offshore Struct 2016. https://doi.org/10.1080/17445302.2015.1035164.

[23] Kang KY, Choi KH, Choi JW, Ryu YH, Lee JM. Explosion induced dynamic responses of blast wall on FPSO topside: Blast loading application methods. Int J Nav Archit Ocean Eng 2017. https://doi.org/10.1016/j.ijnaoe.2016.08.007.

[24] Kang KY, Heo Y, Rogstadkjernet L, Choi KH, Lee JM. Structural Response of Blast Wall to Gas Explosion on SemiConfined Offshore Plant Topside. Int J Struct Stab Dyn 2017. https://doi.org/10.1142/S0219455417500213.

[25] Yang R, Khan F, Yang M, Kong D, Xu C. A numerical fire simulation approach for effectiveness analysis of fire safety measures in floating liquefied natural gas facilities. Ocean Eng 2018. https://doi.org/10.1016/j.oceaneng.2018.03.052.

[26] Kim WK, Mogi T, Dobashi R. Fundamental study on accidental explosion behavior of hydrogen-air mixtures in an open space. Int J Hydrogen Energy 2013. https://doi.org/10.1016/j.ijhydene.2013.03.101.

[27] Zhang S, Zhang Q. Influence of geometrical shapes on unconfined vapor cloud explosion. J Loss Prev Process Ind 2018. https://doi.org/10.1016/j.jlp.2018.01.004.

[28] Recommended practice for classification of locations for electrical installations at petroleum facilities classified as class I, zone 0, zone 1, and zone 2. API Recomm Pract 1997.

[29] Failure frequency guidance: process equipment leak frequency data for use in QRA. DNV 2012.

[30] International Association of Oil and Gas Producers. Ignition probabilities. Risk Assess Data Dir 2010.

[31] Paik JK. Advanced Structural Safety Studies: With Extreme Conditions and Accidents. Springer, 2019.

[32] Matland A. Suggestion of a new definition of risk in the frameworks regulations: possible implications for the process of establishing fire and explosions loads to be used as a basis for design. Master's thesis, University of Stavanger, Norway, 2013.

[33] Book TG. Methods for the determination of possible damage to people and objects resulting from releases of hazardous materials. Report CPR E, 1992. 
Appendices

Table A.1

60 leak scenarios sampled by LHS method

\begin{tabular}{|c|c|c|c|c|c|c|}
\hline Scenario & Equipment & Leak position coordinates (m) & Leak direction & $\begin{array}{l}\text { Leak rate } \\
(\mathrm{kg} / \mathrm{s})\end{array}$ & $\begin{array}{l}\text { Wind direction } \\
\text { (deg.) }\end{array}$ & $\begin{array}{l}\text { Wind speed } \\
(\mathrm{m} / \mathrm{s})\end{array}$ \\
\hline 1 & Crude daily tank & $(111.25,1.75,30.75)$ & $-\mathrm{X}$ & 0.882 & 40.986 & 4.872 \\
\hline 2 & Crude daily tank & $(111.25,1.75,30.75)$ & $-\mathrm{X}$ & 8.900 & 105.935 & 4.541 \\
\hline 3 & Electric dehydrator & $(112.25,13.75,30.75)$ & $+\mathrm{y}$ & 0.172 & 5.346 & 5.204 \\
\hline 4 & Electric dehydrator & $(112.25,9.75,30.75)$ & $-y$ & 0.476 & 203.931 & 6.089 \\
\hline 5 & Electric dehydrator & $(112.25,13.75,30.75)$ & $+y$ & 0.557 & 56.395 & 5.536 \\
\hline 6 & Crude daily tank & $(115.25,1.75,33.45)$ & $+\mathrm{Z}$ & 2.862 & 104.395 & 5.121 \\
\hline 7 & Crude daily tank & $(115.25,1.75,33.45)$ & $+\mathrm{z}$ & 0.436 & 124.646 & 1.929 \\
\hline 8 & Crude daily tank & $(115.25,-2.25,30.75)$ & $-y$ & 0.821 & 135.466 & 7.873 \\
\hline 9 & Crude daily tank & $(115.25,-2.25,30.75)$ & $-y$ & 0.395 & 20.485 & 7.650 \\
\hline 10 & Crude daily tank & $(115.25,4.75,30.75)$ & $+y$ & 1.051 & 78.357 & 3.262 \\
\hline 11 & Crude daily tank & $(117.25,1.75,30.75)$ & $+\mathrm{x}$ & 0.193 & 139.025 & 4.955 \\
\hline 12 & Crude daily tank & $(115.25,1.75,33.45)$ & $+\mathrm{z}$ & 0.051 & 109.574 & 2.375 \\
\hline 13 & Fuel oil transfer pump & $(118.25,-2.25,30.75)$ & $-\mathrm{X}$ & 5.881 & 90.002 & 4.624 \\
\hline 14 & Fuel oil transfer pump & $(118.25,-2.25,30.75)$ & $-\mathrm{X}$ & 0.638 & 60.356 & 3.755 \\
\hline 15 & Fuel oil transfer pump & $(118.25,-2.25,30.75)$ & $-\mathrm{X}$ & 7.294 & 0.662 & 5.950 \\
\hline 16 & Electric dehydrator & $(119.35,11.85,30.75)$ & $+\mathrm{x}$ & 0.253 & 49.367 & 2.867 \\
\hline 17 & Process pipeline & $(119.35,7.75,33.75)$ & $-\mathrm{z}$ & 0.355 & 70.466 & 5.867 \\
\hline 18 & Fuel oil transfer pump & $(120.25,-2.25,30.75)$ & $-y$ & 0.780 & 124.685 & 6.535 \\
\hline 19 & Fuel oil transfer pump & $(120.25,-2.25,29.75)$ & $-\mathrm{Z}$ & 0.679 & 104.467 & 1.228 \\
\hline 20 & Fuel oil transfer pump & $(120.25,-2.25,31.75)$ & $+\mathrm{z}$ & 0.030 & 80.257 & 2.177 \\
\hline 21 & Fuel oil transfer pump & $(120.25,-0.25,30.75)$ & $+\mathrm{y}$ & 0.456 & 57.268 & 3.656 \\
\hline 22 & Fuel oil transfer pump & $(120.25,-0.25,30.75)$ & $+y$ & 0.213 & 10.474 & 4.043 \\
\hline 23 & Fuel oil transfer pump & $(120.25,-2.25,30.75)$ & $-y$ & 0.517 & 85.783 & 2.769 \\
\hline 24 & Fuel oil transfer pump & $(122.35,-2.25,30.75)$ & $+\mathrm{x}$ & 4.070 & 83.682 & 3.065 \\
\hline 25 & Fuel oil transfer pump & $(120.25,-2.25,31.75)$ & $+\mathrm{z}$ & 11.327 & 30.672 & 8.922 \\
\hline 26 & Fuel oil transfer pump & $(122.35,-2.25,30.75)$ & $+\mathrm{x}$ & 5.277 & 135.012 & 2.966 \\
\hline 27 & Crude oil thermal treater & $(128.25,11.75,30.75)$ & $-\mathrm{X}$ & 3.466 & 90.031 & 3.360 \\
\hline 28 & Electric dehydrator pre-exchangers & $(128.25,21.75,30.75)$ & $-\mathrm{X}$ & 0.091 & 49.257 & 3.558 \\
\hline 29 & Electric desalter & $(129.25,0.85,30.75)$ & $-\mathrm{X}$ & 0.314 & 124.673 & 1.578 \\
\hline 30 & Electric desalter & $(129.25,0.85,30.75)$ & $-\mathrm{X}$ & 4.674 & 46.267 & 5.370 \\
\hline 31 & Electric dehydrator pre-exchangers & $(132.25,19.85,30.75)$ & $-y$ & 0.294 & 56.783 & 5.038 \\
\hline 32 & Electric dehydrator feed pumps & $(132.25,17.75,28.75)$ & $-\mathrm{X}$ & 0.598 & 111.467 & 5.453 \\
\hline 33 & Electric dehydrator feed pumps & $(133.25,17.75,28.25)$ & $-\mathrm{Z}$ & 0.801 & 57.262 & 5.702 \\
\hline 34 & Electric dehydrator feed pumps & $(133.25,17.75,28.25)$ & $-\mathrm{Z}$ & 6.485 & 67.366 & 0.175 \\
\hline 35 & Electric dehydrator feed pumps & $(133.25,19.75,28.75)$ & $+\mathrm{y}$ & 0.841 & 54.732 & 0.877 \\
\hline 36 & Electric dehydrator feed pumps & $(133.25,17.75,29.25)$ & $+\mathrm{Z}$ & 0.233 & 180.683 & 4.292 \\
\hline 37 & Electric dehydrator feed pumps & $(133.25,15.85,28.75)$ & $-\mathrm{y}$ & 0.375 & 318.367 & 0.526 \\
\hline 38 & Electric dehydrator feed pumps & $(133.25,15.85,28.75)$ & $-y$ & 8.297 & 45.056 & 2.473 \\
\hline 39 & Electric dehydrator feed pumps & $(133.25,17.75,28.25)$ & $-\mathrm{Z}$ & 0.578 & 89.367 & 7.204 \\
\hline 40 & Electric dehydrator feed pumps & $(133.25,17.75,28.25)$ & $-\mathrm{z}$ & 0.699 & 105.366 & 5.619 \\
\hline 41 & Electric dehydrator feed pumps & $(133.25,19.75,28.75)$ & $+\mathrm{y}$ & 7.089 & 90.094 & 5.785 \\
\hline 42 & Electric dehydrator feed pumps & $(135.25,17.75,28.75)$ & $+\mathrm{x}$ & 0.415 & 35.578 & 3.459 \\
\hline 43 & Hydrocyclones & $(134.25,-4.25,30.75)$ & $-\mathrm{x}$ & 0.760 & 40.266 & 6.758 \\
\hline 44 & Electric dehydrator feed pumps & $(135.25,17.75,28.75)$ & $+\mathrm{x}$ & 0.111 & 114.673 & 3.853 \\
\hline 45 & Electric dehydrator feed pumps & $(135.25,17.75,29.25)$ & $+\mathrm{z}$ & 0.497 & 41.472 & 3.952 \\
\hline 46 & Electric dehydrator pre-exchangers & $(135.25,21.75,30.75)$ & $+\mathrm{X}$ & 0.861 & 15.366 & 2.670 \\
\hline 47 & Hydrocyclones & $(136.25,-3.25,30.75)$ & $+\mathrm{y}$ & 0.719 & 91.367 & 4.458 \\
\hline 48 & Hydrocyclones & $(136.25,-6.15,30.75)$ & $-y$ & 0.152 & 97.237 & 2.572 \\
\hline 49 & Crude oil thermal treater & $(137.25,13.65,30.75)$ & $+y$ & 0.010 & 140.266 & 4.126 \\
\hline 50 & Crude oil thermal treater & $(137.25,9.25,30.75)$ & $-\mathrm{y}$ & 9.504 & 45.086 & 6.981 \\
\hline 51 & Spec oil/crude oil heat exchangers & $(137.35,20.75,30.75)$ & $-\mathrm{X}$ & 0.618 & 50.366 & 4.375 \\
\hline 52 & Electric desalter & $(137.25,-1.25,30.75)$ & $-\mathrm{y}$ & 0.071 & 52.573 & 7.427 \\
\hline 53 & Electric desalter & $(137.25,2.85,30.75)$ & $+\mathrm{y}$ & 0.537 & 37.636 & 6.312 \\
\hline 54 & Hydrocyclones & $(138.25,-4.25,30.75)$ & $+\mathrm{x}$ & 0.740 & 125.588 & 2.079 \\
\hline 55 & Spec oil/crude oil heat exchangers & $(138.25,19.85,30.75)$ & $-\mathrm{y}$ & 0.274 & 46.683 & 2.276 \\
\hline 56 & Spec oil/crude oil heat exchangers & $(138.25,21.75,30.75)$ & $+y$ & 0.132 & 95.703 & 4.707 \\
\hline 57 & Spec oil/crude oil heat exchangers & $(138.25,20.75,31.75)$ & $+\mathrm{Z}$ & 0.334 & 104.936 & 4.209 \\
\hline 58 & Spec oil/crude oil heat exchangers & $(138.25,20.75,31.75)$ & $+\mathrm{Z}$ & 1.654 & 320.388 & 5.287 \\
\hline 59 & Crude oil thermal treater & $(145.25,11.75,30.75)$ & $+\mathrm{X}$ & 2.258 & 97.367 & 3.163 \\
\hline 60 & Electric desalter & $(145.25,0.85,30.75)$ & $+\mathrm{x}$ & 0.659 & 276.368 & 4.790 \\
\hline
\end{tabular}


Table A.2

Sample calculations of explosion frequency in 60 leak scenarios

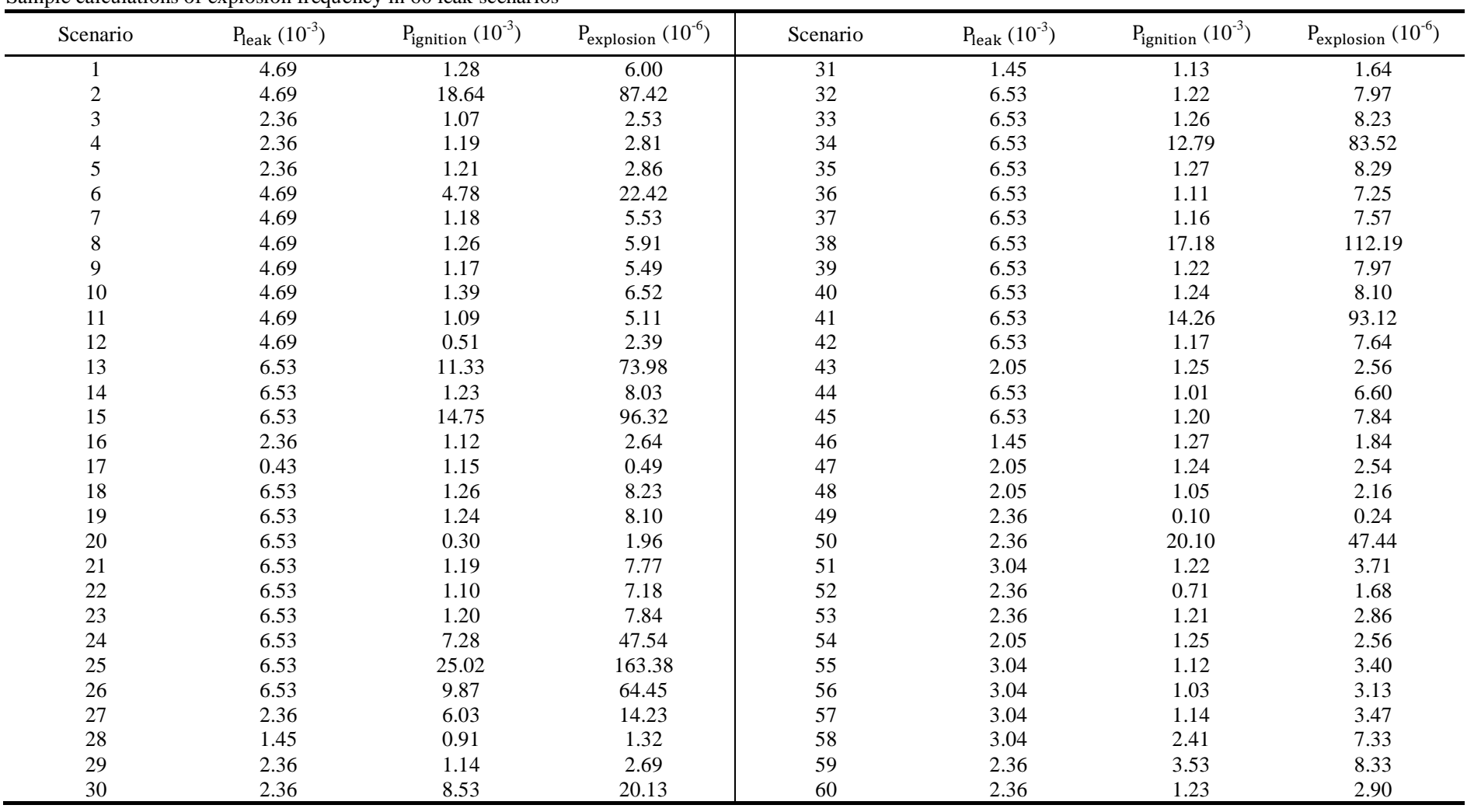

